\title{
Determination of Suitable Sites for Establishment of Large-Scale Concentrated Solar Power Plants in Kenya
}

\author{
Joan Njeri Gathu*, Patroba Achola Odera, Edward Hunja Waithaka \\ Department of Geomatic Engineering and Geospatial Information Systems, Jomo Kenyatta University of Agriculture and \\ Technology, Nairobi, Kenya \\ Email: ${ }^{\star}$ joangathu@gmail.com
}

How to cite this paper: Gathu, J.N., Odera, P.A. and Waithaka, E.H. (2017) Determination of Suitable Sites for Establishment of Large-Scale Concentrated Solar Power Plants in Kenya. Natural Resources, 8, 1-23. http://dx.doi.org/10.4236/nr.2017.81001

Received: December 9, 2016

Accepted: January 3, 2017

Published: January 6, 2017

Copyright $\odot 2017$ by authors and Scientific Research Publishing Inc. This work is licensed under the Creative Commons Attribution International License (CC BY 4.0).

http://creativecommons.org/licenses/by/4.0/

\begin{abstract}
The demand for energy in Kenya, especially for electricity, is increasing rapidly due to population growth, decentralization of governance, and technological and industrial development. Hydroelectricity, the core source of power, has proved unreliable due to the rapid climate change. In response, the country has ventured into other renewable sources to counter the issues posed by the alternative nonrenewable sources such as unreliability, high costs, and environmental degradation as seen with the use of diesel and kerosene. The purpose of this research is to determine the viability of setting up a large-scale concentrated solar power plantation in Kenya that will assist in stabilizing Kenya's energy demand and supply as well as increase its affordability. The project is divided into three phases. The first phase conducts an overlay analysis to determine the Kenya's solar energy potential. The results show that the northern region has the highest potential. The second step involves the creation of an exclusion mask which eliminates the unsuitable land forms and Land Use Land Cover. Based on the results, the best ten sites are situated in Turkana and Marsabit counties. The final phase involves the evaluation of the potential capacity of power that could be generated per square kilometer. The study finds out that the potential varies based on the technologies: parabolic trough, linear Fresnel reflector, or dish systems.
\end{abstract}

\section{Keywords}

Concentrated Solar Power, Solar Energy, Direct Normal Irradiance, Digital Elevation Model, Land Use Land Cover, Kenya

\section{Introduction}

The assessment of Africa's current and future access to renewable energy has 
been extensive although the comprehensive approaches to estimating the production potentials are few and lack transparency. Based on the World Sunshine Map, Africa experiences more hours of sunshine annually than any other continent due to the presence of the Sahara, Kalahari, and Namib deserts [1]. In spite of this, the International Energy Agency observes that the continent, especially Sub-Saharan Africa, has the largest population with no access to electricity in spite of the potential [2]. This study aims at overcoming this gap by defining the suitable locations for setting up solar power plants. The results will be suitable for transparent solar energy modeling and system analysis, which forms the basis for appropriate energy planning.

The challenge of the lack of access to energy is acute in Sub-Saharan Africa based on a report by the International Energy Agency, IEA. According to IEA, about 585 million of the population in this region cannot access electricity as the rate of electrification is as low as $14.2 \%$, especially in rural areas [2]. In East Africa, the World Bank estimates that only $23 \%$ of Kenyans, $14.8 \%$ of Tanzanians, and $10.8 \%$ of Rwandans can access electricity [1]. While the respective governments have strived to connect more people to the grid, the rate of population growth has ensured that the figures remain relatively constant. A majority of the population still uses costly and environmental unfriendly forms of energy for lighting and cooking such as diesel and kerosene [3].

The Kenya's renewable energy sector is one of the most active in Africa. Since 2009 , the national investment has grown from virtually zero to about US $\$ 1.3$ billion by the end of 2010 across technologies such as geothermal, wind, biofuels, and small-scale hydropower [1]. In Africa, Kenya is the first country to indulge in geothermal and a world leader based on the number of solar power plants installed annually. Among these technologies, the solar production is being funded by the government and foreign investors to supplement the national grid. The largest solar production station has been set up in Garissa, a town located in northeast Kenya, to produce $50 \mathrm{MW}$ [4]. The government has identified nine other sites that, once completed, they will provide enough energy to power about half the population [5]. Through the Rural Electrification Program coined by the Ministry of Energy in 2006, the government has planned to accelerate the rate of rural electrification through the promotion of the renewable energy sources at the grass root level [3]. Today, the industry primarily relies on the government and foreign investors for financing. Therefore, there is a need to raise the market value of the sites to help generate adequate revenue for sustenance and growth in the future.

There are five primary sources of energy in Kenya: hydro which constitutes $44.63 \%$ of the national grid, thermal $31.14 \%$, geothermal $22.71 \%$, imports $0.96 \%$, off-grid $0.37 \%$, and wind $0.2 \%$ [6]. The country's demand for power is increasing steadily due to population growth and decentralization of the economy. This has led to the rise of Independent Power Producers, IPPs (or Non-Utility Generators, NUGs) - privately-owned entities who generate power for sale to utilities and end users [7]. NUGs comprise privately-owned entities, corporations, and 
cooperatives such as rural wind and solar energy producers. Additionally, it includes non-energy industrial concerns that are capable of feeding excess energy into the system [8]. It is important to note that solar energy installed in households and businesses fall under the IPPs.

Until recently, solar power has been elusive to a majority of the rural population due to its unpredictability and lack of education. However, recent advancements have resulted in solar cells that are cheap, robust, and are able to increase wattage from the sunlight absorbed [9]. Additionally, because East Africa is near the equator, it is bombarded with sunlight all the year round. For this reason, Michalena and Hills [1] argue that the sector has attracted social entrepreneurs in an industry that is attracting mainstream investors and venture capitalists who consider it to have an increasingly profitable and bright future. Venture capitalists have entered the industry as the government has removed Value Added Tax (VAT) and has zero-rated the import duty. The removal of VAT and import duty has increased its affordability both among the rich and the poor in both rural and urban areas. Following this, a vibrant market for the energy has developed over years for lighting homes and institutions.

According to Oxford Business Group [10], the growth in the market has increased the rate of evolution of solar technologies, especially the photovoltaic, PV, panels (or simply solar cells). The term "photovoltaic" is derived from the physical process whereby the conversion of light (photons) to electricity (voltage) occurs through the so-called "PV effect" [11]. They convert sunlight into electrical power. The traditional PV panels were made from silicon (usually flat-platted) and are still considered to be the most efficient. The second generation cells are known as thin-film cells as they are manufactured from amorphous silicon or non-silicon materials, for instance, cadmium telluride [4]. The third generation solar cells are being made from different materials apart from silicon, for example, solar dyes, solar inks, and conductive plastics.

In 2005, a preliminary survey conducted showed that the annual demand for PV panels was 500-kilowatt peak $(\mathrm{kWp})$ and projected to grow at a rate of $15 \%$ annually. This estimate has been realized through initiatives such as M-Kopa and Lighting Africa that have partnered with the International Finance Corporation (IFC) and World Bank [9] [12]. In particular, M-Kopa has introduced two schemes: pay-as-you-go and microfinance. In the pay-as-you-go, customers are required to pay a deposit of 3500 Kenyan Shillings (approximately \$50) and then pay 50 Kenyan Shillings (about $\$ 0.5$ ) on a daily basis for one year [12]. They are allowed to take the system home after the initial deposit. On the other hand, the microfinance scheme stems from relationship-based banking where the rural population is accorded an opportunity for saving money over a period [4]. MKopa has used this scheme to set up a concentrated solar power project for a group of people [12]. Some international companies have indulged in solar energy production in Kenya, and the larger East Africa.

It is crucial to note that the amount of solar energy at a place depends on the solar radiation. According to the International Energy Agency, solar radiation is 
the electromagnetic energy released by the sun [3]. Alternatively, it is the measure of the rate at which the radiant energy is incident on a surface per unit area, $\mathrm{w} / \mathrm{m}^{2}$ [13]. PV panels are affected by the surrounding temperature, which is mainly a product of the level of sunlight and the ambient temperature. While the strength and length of sunlight are the primary factors that influence the power efficiency of PV panels, a couple of other environmental factors can reduce this efficiency and, in the process, lower the energy output. For instance, there is a $1.1 \%$ decrease in the peak output per degree if the ambient temperature reaches $42^{\circ} \mathrm{C}$ [10]. Other factors include aerosols, snow and clouds, latitude, and the season.

Since 2011, the average cost of a completed PV system has reduced by $33 \%$. The prices of the panels have reached grid parity, that is, the point at which the cost of generating solar power is equal or less than the cost of purchasing power from Kenya Power [14]. Grid parity has been facilitated by various project and others that are underway. For instance, the United Nations Environment Program, UNEP, has installed on-roof $515 \mathrm{kWp} \mathrm{PV}$ solar network that powers the administration block [8]. The Garden City's solar system has installed 3364 solar panels on the carports to generate $1450 \mathrm{mWp}$ annually. Strathmore University has begun an installation of a $600 \mathrm{kWp}$ rooftop and grid-connected solar plant financed by the French Development Agency, AFD. Moreover, two Chinese companies, Jinko Solar Holdings and Jiangxi Corporation for International Economic \& Technical Limited, are set to join forces to construct a $50 \mathrm{MW}$ power plant in the country. Lastly, the Chinese Dongfang Electrical International Corporation, DEC, has expressed interests in setting up a $\$ 100,000$ (50 MW) solar power plant in Nakuru County and connecting it to the national grid.

This study was aimed at determining the suitable sites for setting up a large scale power plant incorporating the concentrated solar power technology in Kenya. To achieve this, the solar energy potential of Kenya was first determined using the Direct Normal Irradiance, land suitability, digital elevation model and population. After which, the optimum prime site locations were identified for the establishment of a large scale solar plantation and their potential capacity calculated.

Concentrated solar power (CSP) is an electricity generation technology that uses heat provided by solar irradiation concentrated on a small area. Today, concentrated solar power plants are increasingly becoming popular due to high efficiency, excellent scale-up potential, and lower operating costs [2]. In principle, the system collects energy from the sun using long, rectangular, and Ushaped mirrors tilted towards the sun. Sunlight is focused onto tubes (receivers) that run along the length of the mirrors. The reflected light heats up the fluid in the tubes. The heated fluid then boils water concentrated in a typical steam turbine generator for electricity production [1]. There are three major types of concentrated systems: parabolic trough, linear Fresnel reflector, and dish/engine systems. In the parabolic trough system, the receiver tubes are placed along the focal lines of the parabolic mirrors. In the linear Fresnel reflector system, the re- 
ceiver tubes are placed above the mirrors to allow greater mobility in tracking the sun [10]. Dish system is composed of a parabolic dish-shaped concentrator (like a satellite dish) that reflects direct solar irradiation onto a receiver at the focal point of the dish.

\section{Methodology}

A study was conducted to determine the specific site specifications of setting up a concentrated solar power plant. It requires regions that experience high direct solar irradiance to work productively. It is worth noting that only strong and direct sunlight can be concentrated to the right temperatures and as a result, works well in the regions between $40^{\circ}$ north and south of the equator [11]. When it comes to the geographical topography requirements, it was observed that the maximum slope of solar fields for CSP technology is $<1-2$ for parabolic trough, $<2-4$ for linear Fresnel, and 10\% or more for dish system [11]. In more complex geographies, the uncertainty of yearly DNI can be as high as $\pm 12 \%$, especially in regions where aerosol content is high and dynamically changing. For example, the possibility is high in humid regions, high latitudes, regions with occasional occurrences of snow, and urbanized and industrialized areas [15]. Concentrated Solar Panels take up a lot of physical space as the machinery as voluminous in nature. Thus, to set up such an infrastructure would require a vast acreage of land. Thus, land requirement is significant, with previous experience indicating that around $2 \mathrm{ha}\left(20,000 \mathrm{~m}^{2}\right)$ is needed for every $1 \mathrm{MW}$ in the case of parabolic trough systems [16]. Other factors, particularly those relating to the ability to connect to the national grid, are essential requirements [17].

Data was captured and prepared for analysis. The raster datasets used were Direct Normal Irradiance (DNI), Land Use Land Cover data, SRTM's 90 m Digital Elevation Model, LandScan's Population, and KENSOTER's Soil Data. The vector data sets used are road transport, infrastructure, drainage, towns and settlements, and forests and protected areas. Direct Normal Irradiance data was obtained from Solar and Wind Energy Resource Assessment (SWERA) Database whose spatial resolution is $10 \mathrm{~km}^{2}$. Digital Elevation Model was obtained from NASA's Shuttle Radar Topography Mission (SRTM) elevation data, whose spatial resolution is $90 \mathrm{~m}$ by $90 \mathrm{~m}$. Population data was obtained from Landscan which is provided by the Oak Ridge National Library, whose spatial resolution is 1 $\mathrm{km}^{2}$. Soil data was obtained from Kenya soil and terrain database for Kenya (KENSOTER) whose scale lies at 1:1M. Roads in Kenya have been obtained from Kenya Roads Board (KRB), a government organization which manages Kenya road networks for socio-economic development. Land use land cover, settlements, towns, protected areas, forests and drainage were obtained from National Environment Management Authority (NEMA) and World Resources Institute (WRI).

The methodology is composed of three phases. The first phase involves the analysis of the two key factors: Direct Normal Irradiance (DNI) and digital elevation model (DEM) to get the solar energy potential with all other dynamics 
assumed constant. This was achieved by first reclassifying the DNI and DEM based on their suitability for the placement of a power plant. During reclassification of DNI, it was put into account that only strong direct sunlight can be concentrated to the temperatures required for electricity generation. The minimum direct normal irradiance levels for an economic CSP plant is $2000 \mathrm{kWh} / \mathrm{m}^{2} /$ year [16]. The higher the irradiance above $2000 \mathrm{kWh} / \mathrm{m}^{2} /$ year is, the higher the suitability is. The DEM was then used to calculate the slope. The maximum slope of solar fields for CSP technology is $<1-2$ for parabolic trough, $<2-4$ for linear Fresnel, and $10 \%$ or more for dish system [11]. The slope was reclassified such that slope between 1 and 4 are more suitable. The reclassified slope and reclassified direct normal irradiance were then overlaid and equally analyzed to produce the solar potential.

The second phase involved the creation of exclusion mask. The first process involved the creation of buffers of the unsuitable features based on the distances described in Table 1. The buffers were combined to create an exclusion mask. The distances from features such as drainage systems, roads and towns allow for disasters such as flooding, provide room for expansion and growth as well as inaccuracies in the delineation of features especially because some features do not have a distinct boundary but rather diminish gradually. Table 1 displays the safe distances used for the creation of the exclusion mask.

The exclusion mask was then used to eliminate areas that are not suitable for setting up a solar power installation. To further narrow down the site and get specific locations, the DNI values of the identified areas were used. A further analysis using ancillary data and prior knowledge of the country's state of affairs helped eliminate areas with high security risks such as terrorism and insecure

Table 1. Exclusion mask criterion.

\begin{tabular}{cc}
\hline Feature & Buffer distance in meters [18] \\
Wetlands & 500 \\
Lakes & 500 \\
Rivers & 500 \\
Sandy and very clayey soil & 1000 \\
Forests & 1000 \\
Protected areas & 2000 \\
Agriculture & 2500 \\
Roads & Excluded \\
Unsuitable land use land cover & Excluded \\
Densely populated areas & Excluded \\
Unsuitable slope & \\
\hline
\end{tabular}


areas known for banditry and social conflicts such as the identified areas bordering the Somalia border.

The third phase involved calculating the power capacity of each identified site based on the CSP technology specifics. A case study of a solar plant with solar power area coverage of $1 \mathrm{~km}^{2}$ was used across three major CSP technologies: parabolic trough, linear Fresnel reflector, and dish/engine systems. The formula below was used to determine the potential power generation within the identified sites [19].

$$
\begin{gathered}
\text { Power }=\text { DNI } \times \text { Efficiency } \times \text { Panel Area }{ }^{*} \times \text { Concentration Factor } \\
\text { Panel Area }=1 \mathrm{Km}^{2}
\end{gathered}
$$

The input parameters were guided by the technology-specific parameters shown in Table 2 which illustrates the specifics of each CSP technology used to calculate the power potential. The results were then analyzed based on the current and predictable demands of the country to identify the overall benefit of setting up the solar energy power plant in Kenya in comparison to the current state of energy production.

\section{Results}

The first phase involved the reclassification and analysis of DNI and DEM. The DEM and DNI were first prepared by clipping them to fit the area of interest. DEM was then used to generate the slope in the units of degrees. Slopes in kenya range from $0-69.71^{\circ}$. It is observed that the western and south western regions of Kenya are generally hilly with most of these regions falling above slopes of $1.36^{\circ}$. Whereas in the south eastern, north eastern, eastern and northern regions of Kenya are generally flat and undulating with slopes generally being below $1.36^{\circ}$ as shown in Figure 1.

Conversely, for a CSP plant, a slope gradient of between $1-4$ is suitable. Based on these general CSP specifications, the slope was then reclassified based on a suitability range of between 1 and 10.1 registered as the least suitable condition and 10 as the best suitable condition for the setting up of a CSP plant. Thus the areas that fell between slope of $1-4^{\circ}$ fell within the ranges of 7 and 10 as they are best suitable. The results on reclassifying the slope are shown in Figure 2. From the observations made, the very flat areas and the very hilly areas were classified as least suitable and the gentle slopes of between $1-4^{\circ}$ were classified as the best suitable as shown in Figure 2.

Table 2. Large scale concentrated solar power technology [20].

\begin{tabular}{cccc}
\hline Technology & Panel efficiency & Concentration factor & $\begin{array}{c}\text { Dimensional } \\
\text { concentration type }\end{array}$ \\
\hline Parabolic trough & $11 \%-16 \%$ & $70-8$ & $2 \mathrm{D}$ \\
Solar tower & $7 \%-20 \%$ & $>1000$ & $3 \mathrm{D}$ \\
Dish sterling & $12 \%-25 \%$ & $>1300$ & $3 \mathrm{D}$ \\
\hline
\end{tabular}




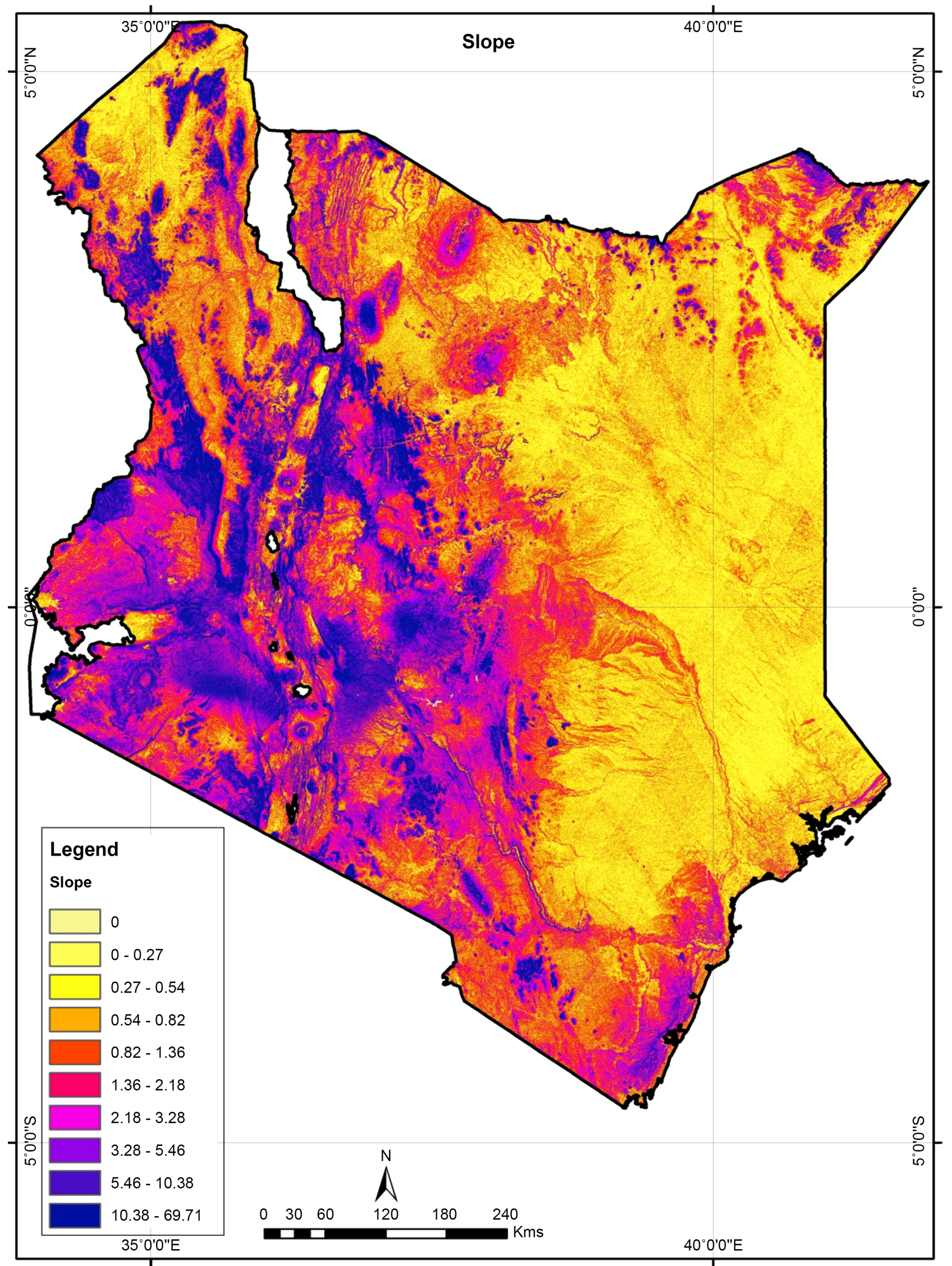

Figure 1. Slope. 
J. N. Gathu et al.

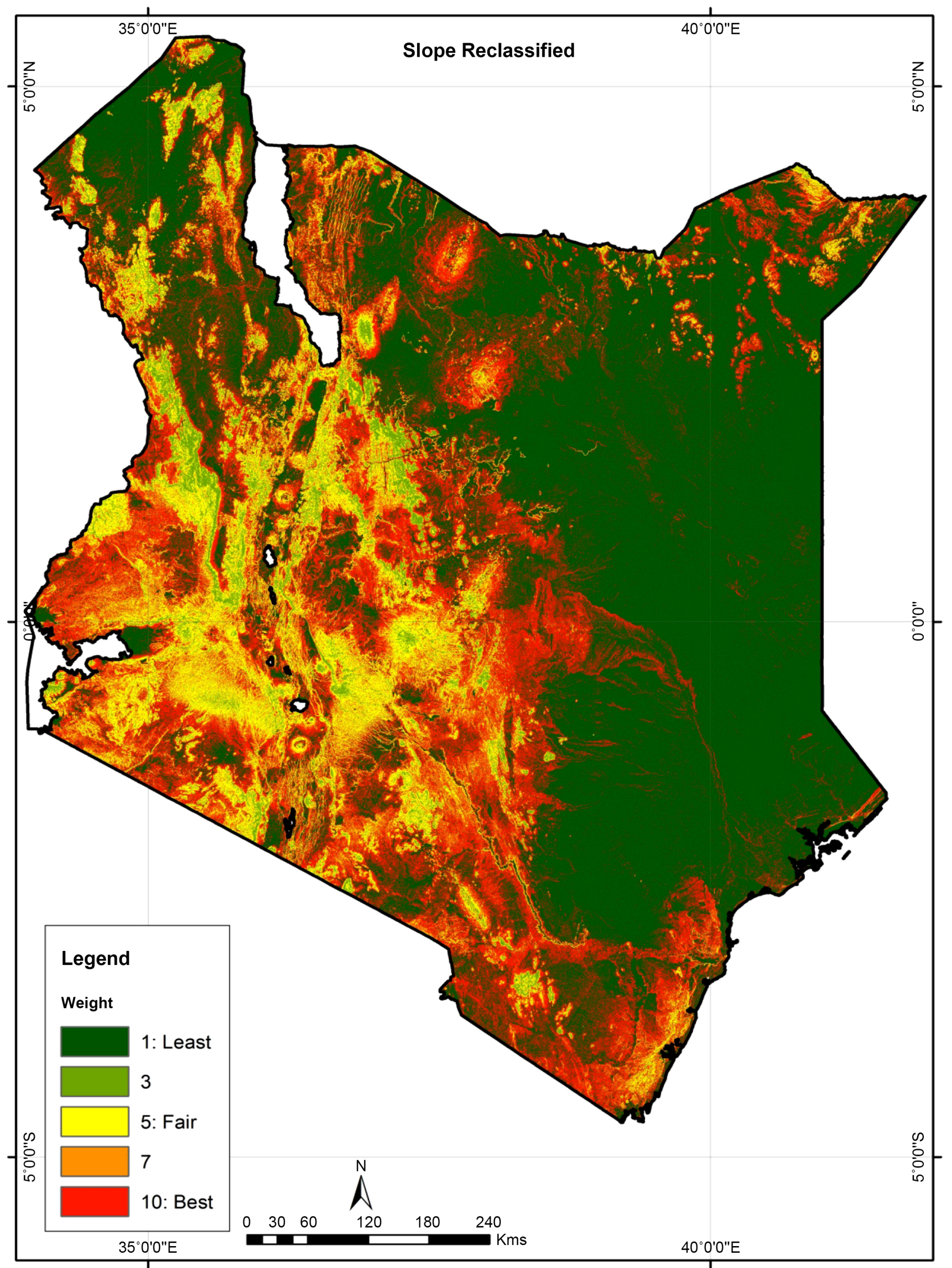

Figure 2. Reclassified slope. 
DNI in Kenya ranges from 1454 - $6649 \mathrm{Wh} / \mathrm{m}^{2}$. As observed in Figure 3, the western parts of Kenya register the lowest DNI. This is attributed to the high cloud cover and humidity within this area. Areas towards the north eastern parts of Kenya, south-wards near the Magadi area and the coastal regions of Kenya register the highest DNI values. These areas record low cloud cover and humidity and experience clear skies most often throughout the year. It is observed that the north eastern region of Kenya has vast land favoring the DNI conditions for setting up the CSP plant.

CSP plants work best within areas with a DNI of $2000 \mathrm{Wh} / \mathrm{m}^{2}$ per year or more [16]. DNI was then reclassified to a similar suitability range of 1 to 10 where by 1 describes the least suitable and 10 the most suitable for setting up a CSP plant. As observed, the western region of Kenya has unsuitable DNI conditions for setting up a CSP plant. However, there is great potential within the north eastern region and along the coastal regions of Kenya as shown in Figure 4.

The reclassified slope and DNI now range in a standardized suitability range of 1 - 10 based on the suitable conditions for setting up a CSP power plant in Kenya based on the ground conditions. The reclassified slope and direct normal irradiance were then overlaid, equally weighted and analyzed. The results were as shown in the Figure 5. It is observed that the mountainous and the western regions of Kenya were eliminated. However, the rest of Kenya is observed to fall within 6 - 10 which falls under the suitability range of moderate to high.

Phase two involved the creation of an exclusion mask. In order to achieve the exclusion mask, the unsuitable landforms and features were identified and their safe distances determined. Features identified were roads, rivers, lakes, unsuitable soils, forests, protected areas and unsuitable conditions such as slope, unsuitable land use and high population density. Buffers were first created individually for each feature respectively after which they were combined to form the exclusion mask which would further be used collectively to eliminate unsuitable areas. The exclusion mask achieved is shown in Figure 6.

The exclusion mask achieved was then used to eliminate the unsuitable areas from the solar potential area results achieved in the first phase. It is observed that the site has greatly reduced in area coverage and the results shown in Figure 7 display areas that are best suitable setting up a CSP plant. It is observed that the northern parts of Kenya have greater potential than the southern regions of Kenya.

The third phase involved narrowing down and identifying the location of the best sites for setting up the CSP plants. Among the identified sites from the results of second phase, the DNI values were used to prioritize the areas. The specific locations of the best 25 suitable sites were identified from the vast area by first clustering the areas and selecting the specific areas with the highest DNI. The identified sites were as shown in Figure 8.

For further analysis, the potential sites needed to be narrowed down further to 10 sites. It is important to note that potential areas identified in the North Eastern parts of Kenya were eliminated due to the insecurity posed by terrorism 
J. N. Gathu et al.

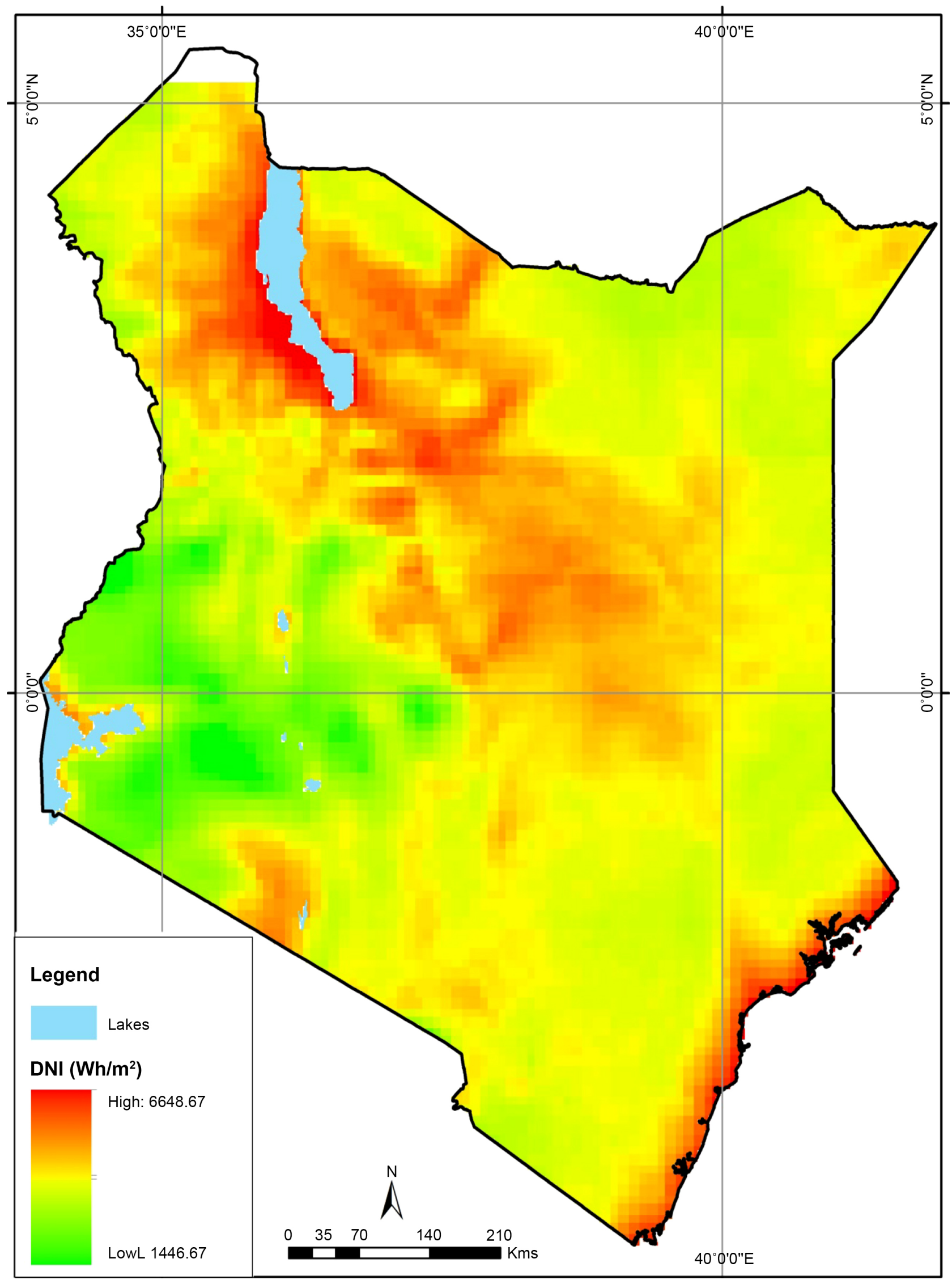

Figure 3. Direct normal irradiance. 


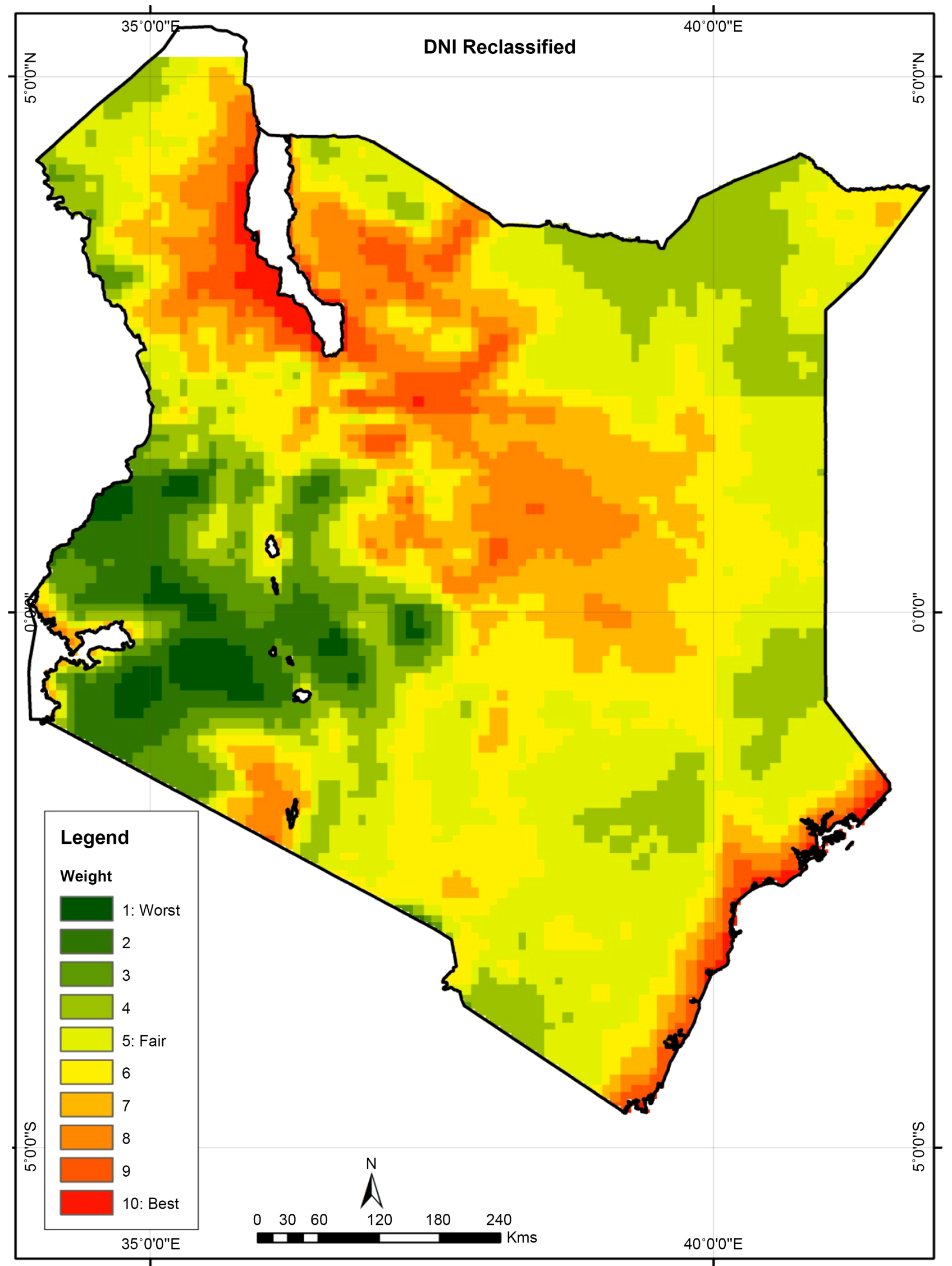

Figure 4. Reclassified direct normal irradiance. 


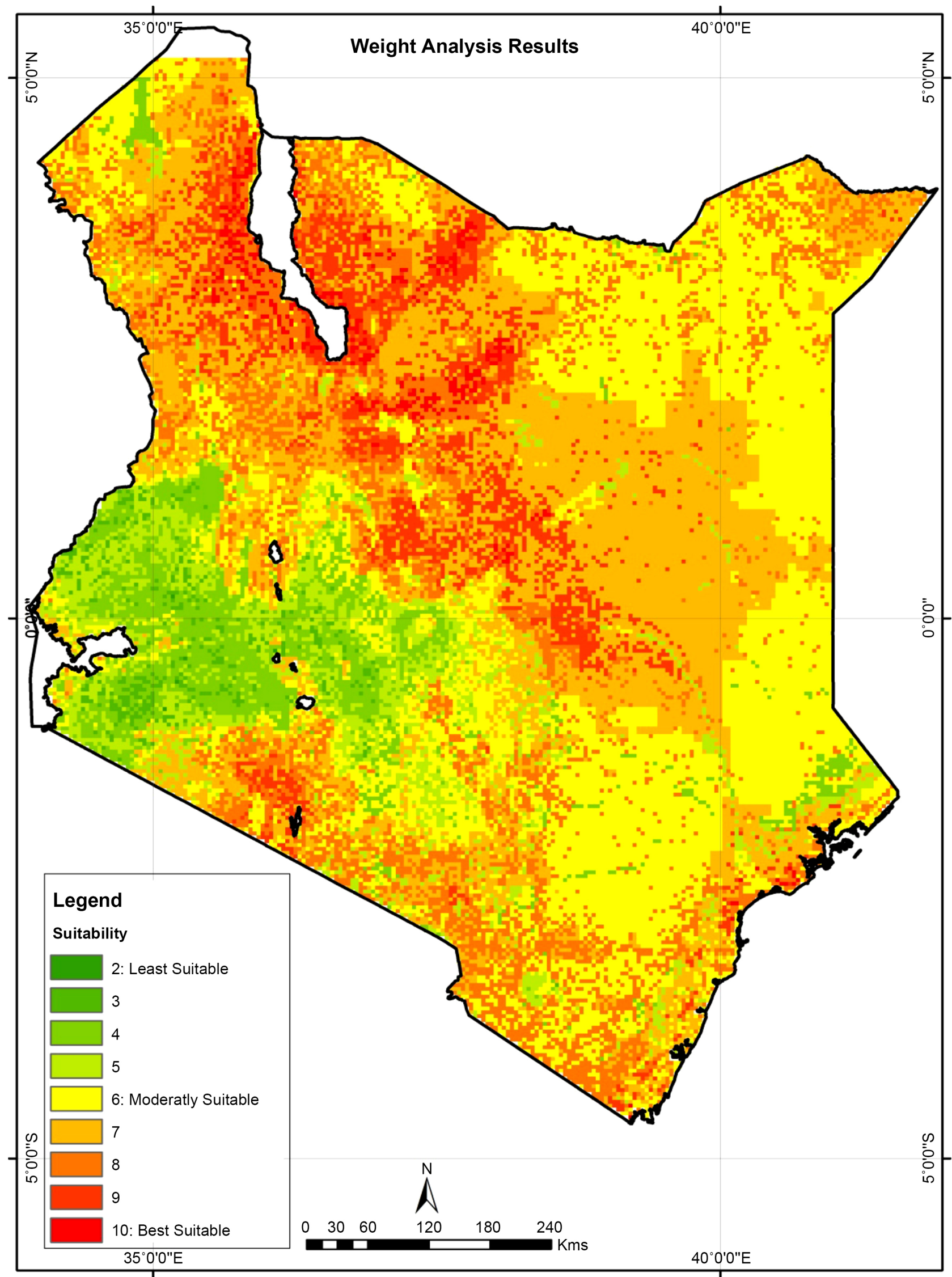

Figure 5. Weight analysis results. 


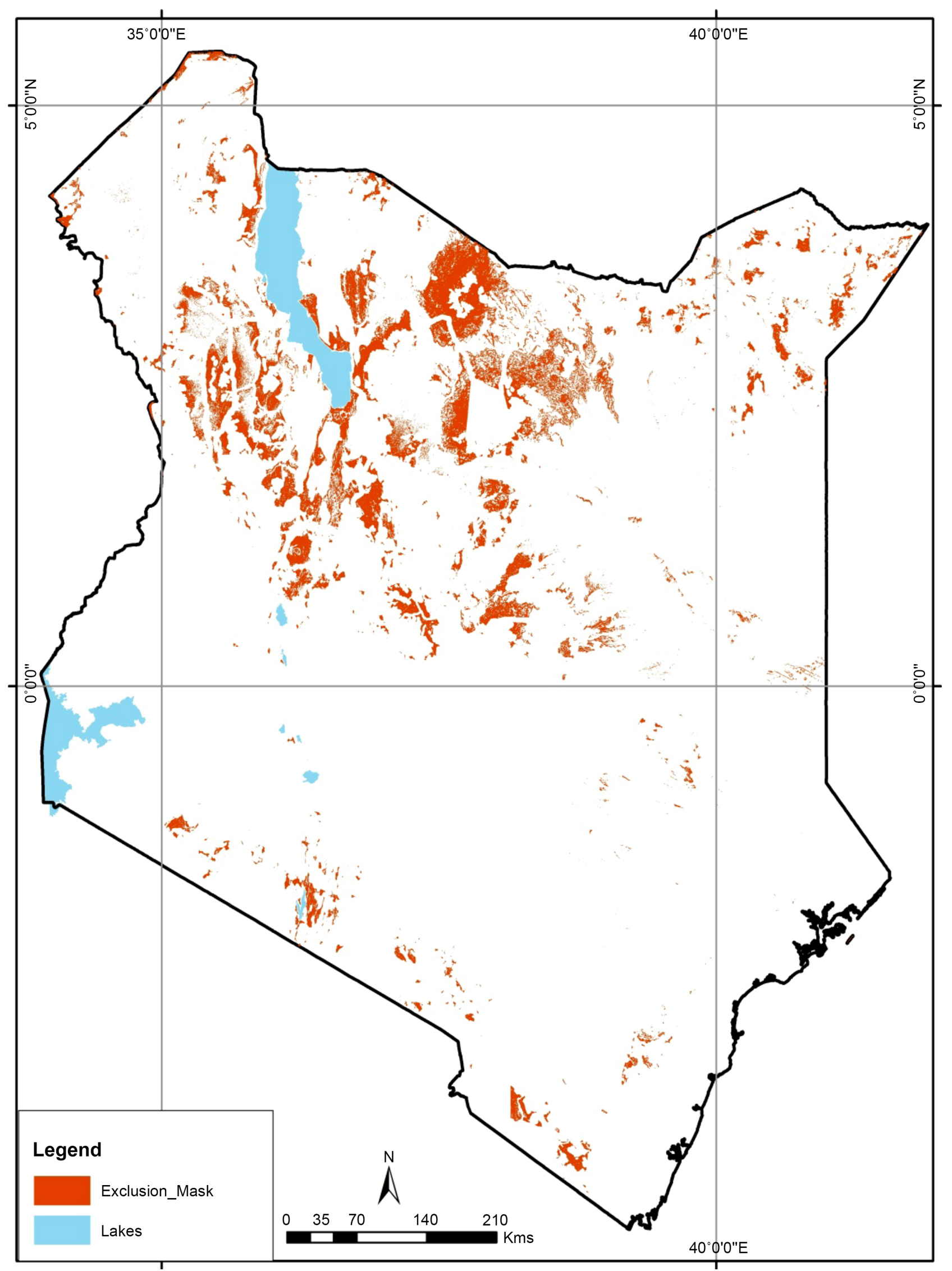

Figure 6. Exclusion mask result. 


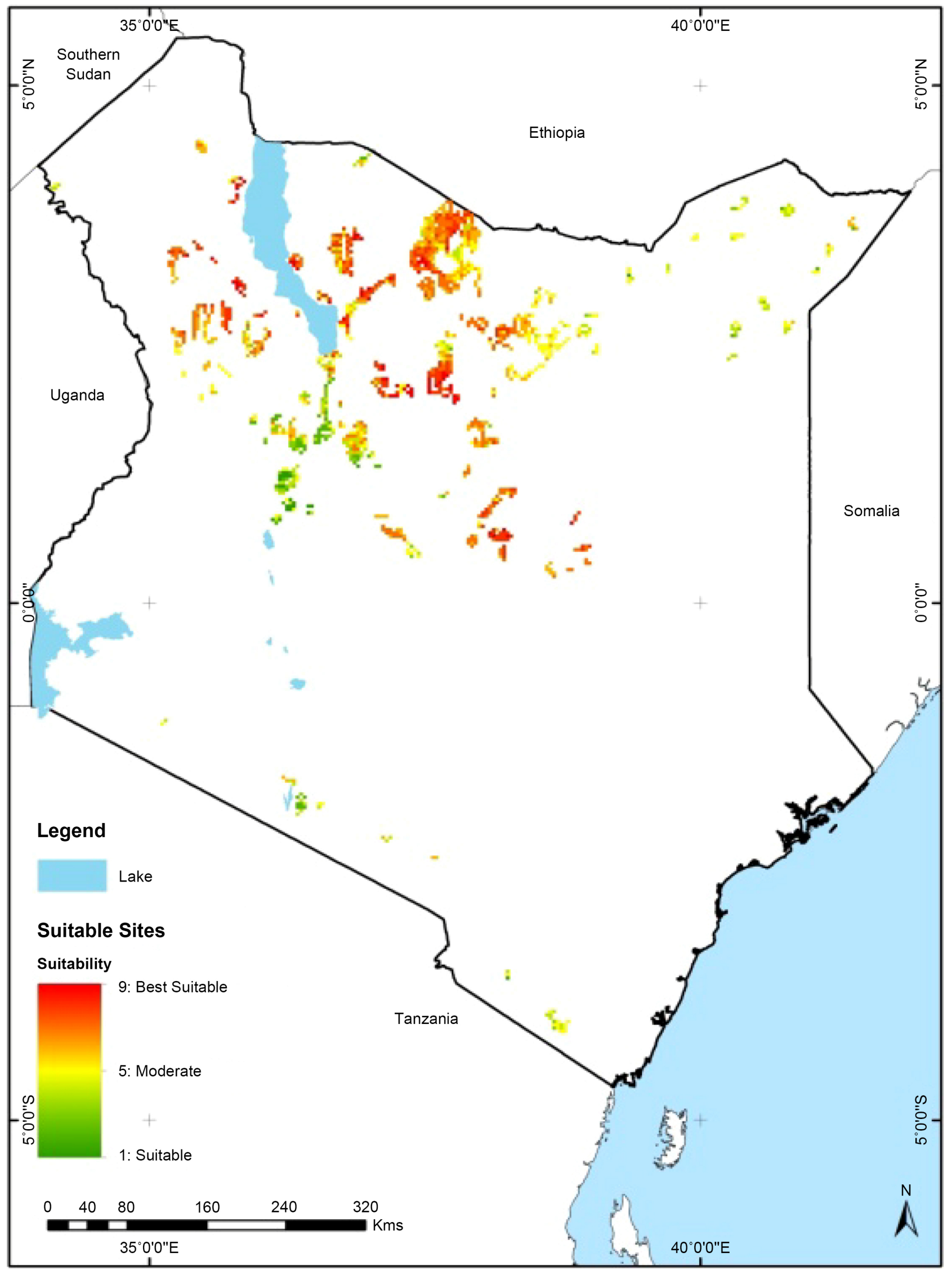

Figure 7. Site results. 


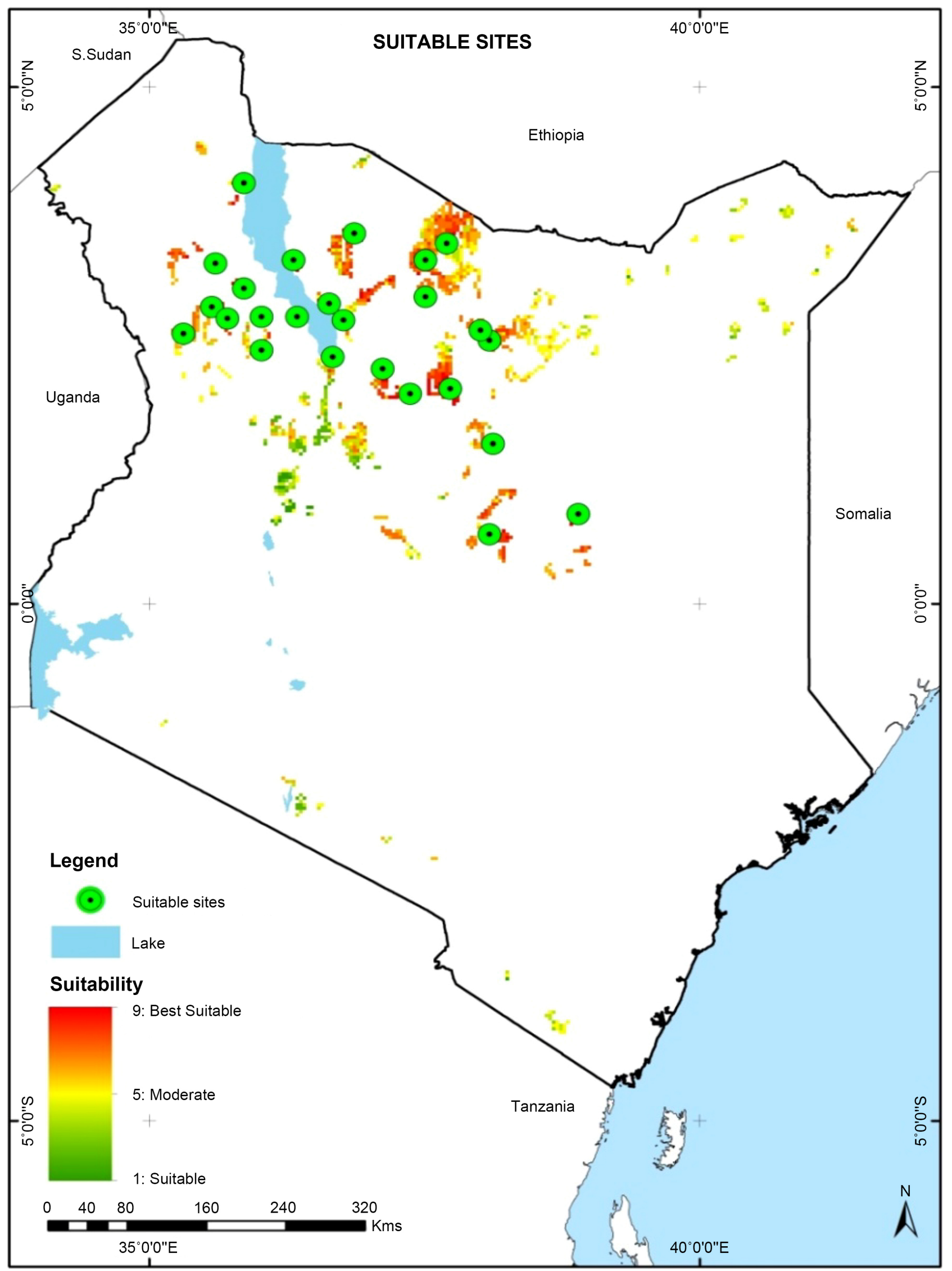

Figure 8. Site suitability. 
threats. By virtue of the DNI values, the best 10 sites were then selected. They were as shown in Figure 9.

Figure 10 pans closer to demonstrate the location of the identified 10 best sites. It is observed that they are widely distributed. These sites were required in the completion of the final phase which involved the realization of the power capacity of each site.

The identified sites lie between latitude $2^{\circ} \mathrm{N}-4.5^{\circ} \mathrm{N}$ and longitude $35^{\circ} \mathrm{E}-$ $38^{\circ} \mathrm{E}$. The geographic coordinates of the 10 best sites are described in Table 3 . The coordinates system used is Geographic WGS 1984.

The final phase was achieved by calculating the potential output capacity on setting up a Concentrated Solar Power installation plant within these identified sites. Using the formula described in Equation (1), the power generated by a 1 $\mathrm{km}^{2}$ panel area within this identified sites was determined [19] based on the 3 commonly used CSP technologies. Table 4 describes the power potential in Megawatt Hours within the 10 sites.

Table 3. Coordinates of the 10 best sites.

\begin{tabular}{lll}
\hline Site & Easting & Northing \\
\hline 1 & 36.63736 & 2.904993 \\
2 & 36.34636 & 2.775659 \\
3 & 35.86136 & 3.050493 \\
4 & 35.86136 & 4.068992 \\
5 & 37.372943 & 2.031993 \\
7 & 36.314027 & 3.325326 \\
8 & 36.023027 & 2.775659 \\
9 & 36.766693 & 2.743326 \\
10 & 37.736693 & 2.080493
\end{tabular}

Table 4. Power generation in the best 10 sites (Mwh).

\begin{tabular}{cccc}
\hline Site & Parabolic trough & Solar tower & Dish sterling \\
\hline 1 & $670-1017$ & $445-1271$ & $763-1590$ \\
2 & $694-1009$ & $441-1261$ & $757-1576$ \\
3 & $677-984$ & $431-1231$ & $738-1538$ \\
4 & $670-974$ & $426-1218$ & $731-1523$ \\
5 & $645-938$ & $410-1172$ & $703-1465$ \\
6 & $631-918$ & $401-1148$ & $689-1435$ \\
7 & $631-918$ & $401-1147$ & $688-1434$ \\
8 & $615-895$ & $391-1118$ & $671-1398$ \\
9 & $612-890$ & $389-1113$ & $668-1391$ \\
10 & $610-887$ & $388-1110$ & $666-1387$ \\
\hline
\end{tabular}




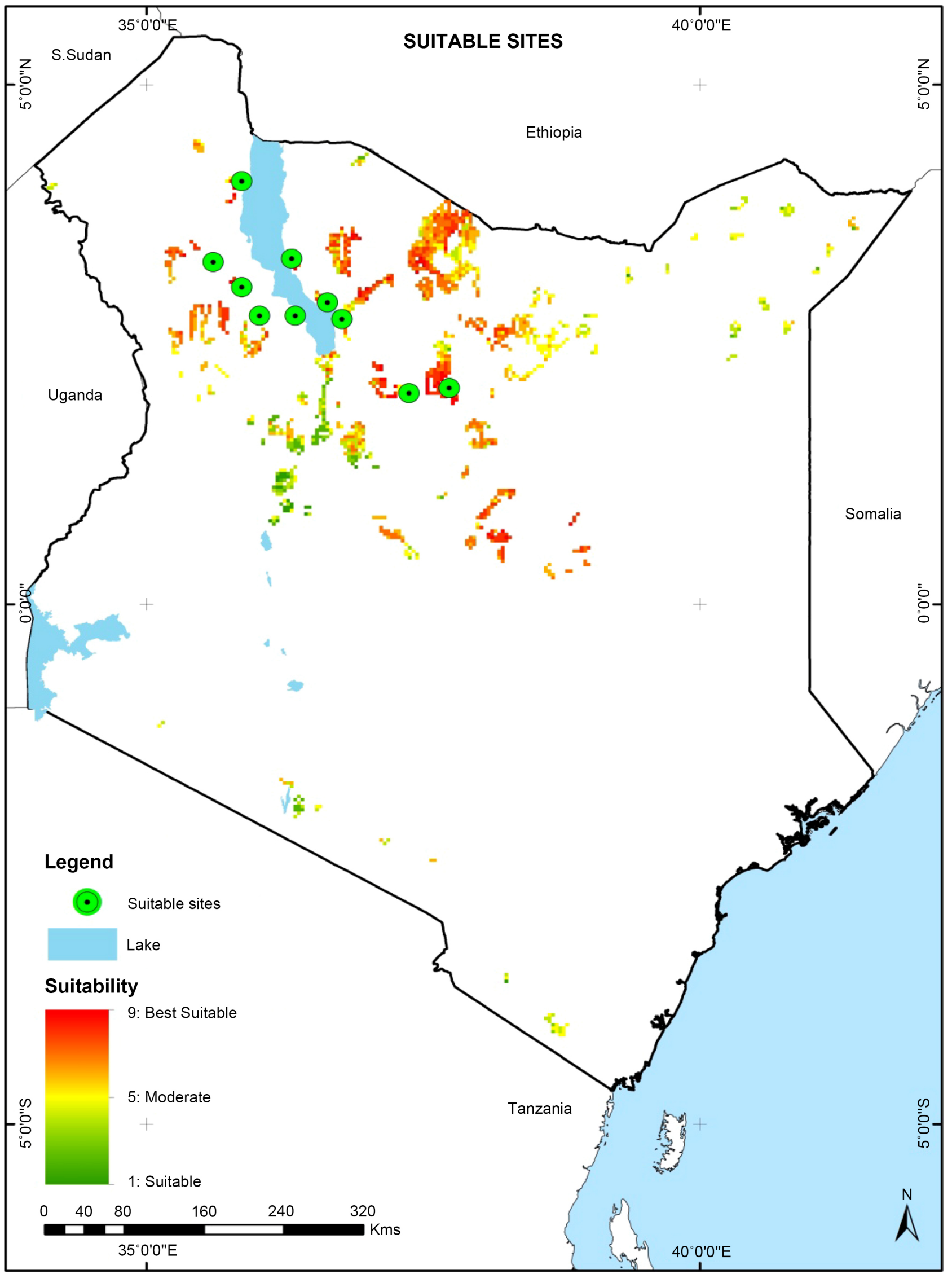

Figure 9. The best 10 suitable sites. 
J. N. Gathu et al.

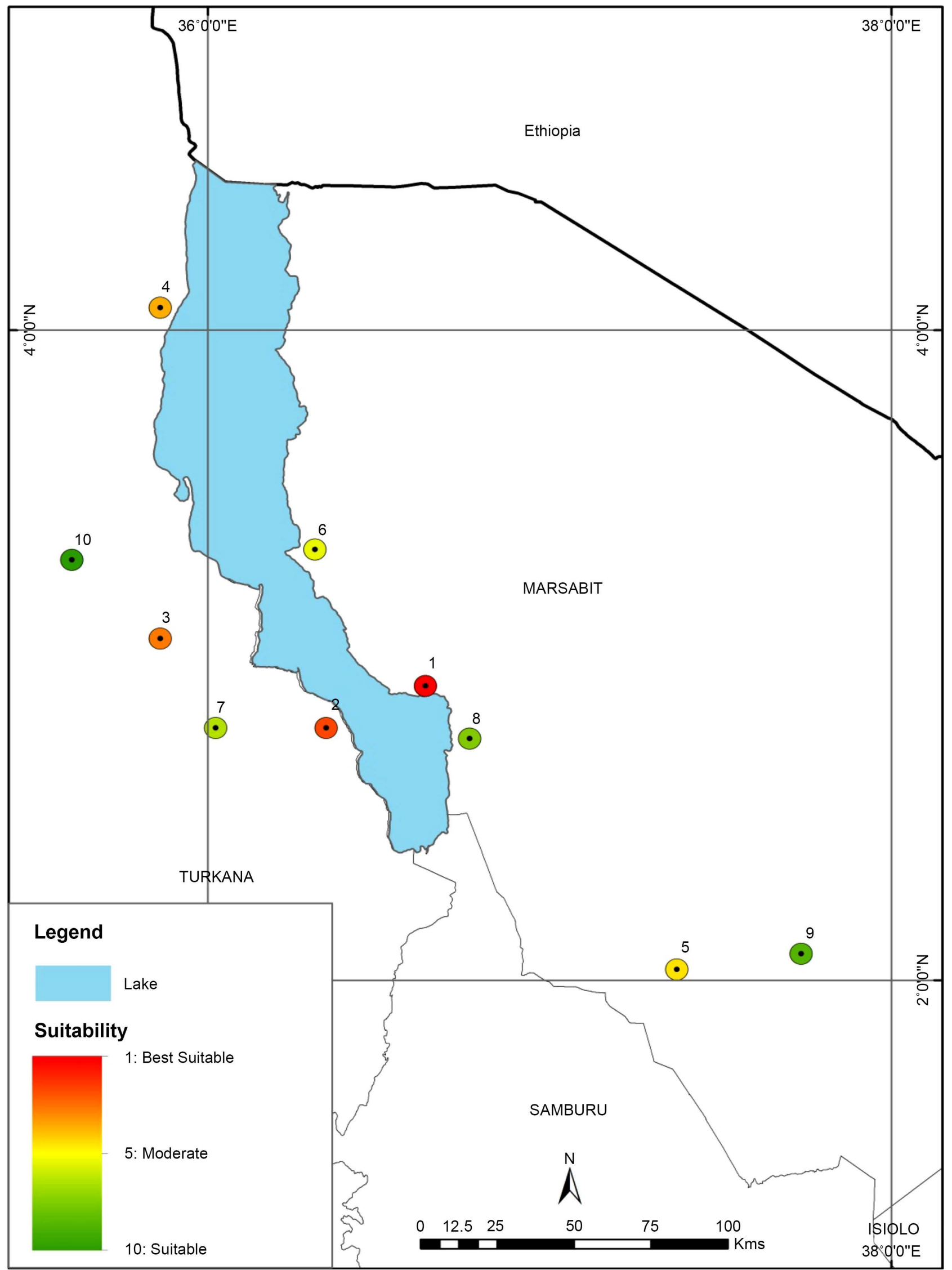

Figure 10. Close up view of suitable sites for concentrated solar power plant installations. 


\section{Discussion}

This research explored the possibility of setting up a concentrated solar energy panel in Kenya. The results are a clear indication that there is great potential for concentrated solar energy in Kenya especially towards the Northern Region, particularly in Turkana and Marsabit counties. The energy potential within the identified 10 best sites across these counties lies between 670 and $1064 \mathrm{MWh}$, 445 and $1329 \mathrm{MWh}$, and 763 - $1662 \mathrm{MWh}$ based on the parabolic trough, solar tower, and dish sterling technologies respectively over a $1 \mathrm{~km}^{2}$ solar panel range. The most commonly used technology is the parabolic trough.

Currently Kenya has a population of approximately 47 million. Out of this, only $23 \%$ of the population is accessible to electricity, which is approximately 11 million people. As at June 2015, Kenya had installed an electricity generation capacity of 2299 MW comprising of hydro (821 MW), thermal (827 MW), geothermal (598 MW), wind (25.5 MW), and co-generation (26 MW), solar (0.57 MW) [21]. Kenya has decreased its generation from fossil fuels as a result of increased geothermal generation. There has been improvement in energy production over the recent years. However, Kenya still imports $18.15 \%$ of its electricity from its neighboring countries to satisfy the current energy demand. The population and industrialization of Kenya is constantly growing. Based on these two facts, there is foreseen need to plan and strategize bridging the growing energy demand and limited supply for energy in Kenya so as to sustain an energy balance.

Investing in solar energy in large scale production will not only increase the energy supply within the country, it will also aid in improving the economy of the country and the surplus energy production used to enhance the country's foreign exchange by exporting energy to its neighboring countries. Areas that are not accessible to solar energy due to distance from the main grid can benefit from off grid.

Kenya's Vision 2030 identifies Energy as a key player in the long-term development of the social, economic and political pillars that will aid tackle challenges such as reduction of poverty and overall improvement of the population welfare. The energy sector's mission is to provide clean, sustainable, affordable, reliable and secure energy services at least cost while protecting the environment. It is envisioned that the following shall contribute towards achievement of Kenya Vision 2030 by:

1) Enhancing power generation capacity;

2) Increasing access to Electricity;

3) Development of new and renewable sources of Energy;

4) Ensuring security of fossil fuel resources; and

5) Capacity building of the Energy sector.

Figure 11 illustrates the boosting impact that solar energy would have in Kenya's power generation if implemented based on the current energy production.

Solar energy investment is thus a solution to maintaining an energy balance in 


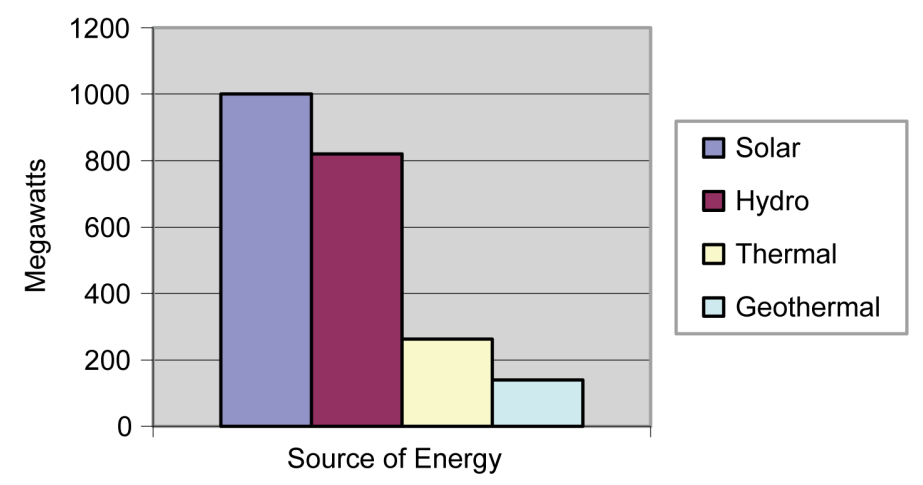

Figure 11. Energy production in Kenya.

Kenya as the countries grows both in number and in the industrial economy. Kenya has thus proven to have great potential especially within the identified sites using the methodology developed to attaining the said objectives of finding the most suitable sites for setting up a large scale solar installation.

\section{Conclusions}

From the methodology, Kenya has a large potential for large-scale concentrated solar power plants, particularly in Turkana and Marsabit counties. The ten best suitable sites were identified. The energy potential within these counties is between 670 and $1064 \mathrm{MWh}, 445$ and $1329 \mathrm{MWh}$, and 763 - $1662 \mathrm{MWh}$ based on the parabolic trough, solar tower, and dish sterling technologies over a $1 \mathrm{~km}^{2}$ solar panel range. It has further been observed that the parabolic trough, solar tower, and dish sterling technologies would produce 17.45, 249.32 and 444.17 Megawatts per second over the same range when CSP uses concentration factors. As Turkana and Samburu are remote areas that are rich in oil deposits, there is no need of introducing CSP investments to promote energy decentralization. If solar power plants were set up, it would help to boost the hydropower sector, and surplus to be exported for foreign exchange. The country will additionally reduce her reliance on diesel and kerosene, as well as the importation of power during the dry seasons.

Currently, we are relying on satellite imagery for DNI data, which is provided free by SWERA. Ground observations are used to improve the satellite data as seen in the developed countries. A good density of weather stations spread across Kenya could improve the DNI data to acquire higher accuracies of between \pm 5 and $10 \%$. However, the limiting factor is the high cost of solar radiation equipment. The government should venture in further research on solar energy and allocate the budget to facilitate research into solar energy.

\section{Acknowledgements}

We would like to thank SWERA, NASA, KENSOTER, WRI and NEMA for providing valuable data sets. J.N.G is grateful to the Jomo Kenyatta University of Agriculture and Technology for the support granted to her to carry out this research. 


\section{References}

[1] Michalena, E. and Hills, J.M. (2015) Renewable Energy Governance: Complexities and Challenges. Springer, London.

[2] Oludhe, C. (2013) Kenya: A Natural Outlook-Chapter 10: Renewable Energy Resource. Elsevier, London.

[3] Onyulo, T. (2015) Solar Power Brightens Residents Prospects in East Africa. Newsweek. http://europe.newsweek.com/kenya-solar-power-clean-energy-476915?rm=eu

[4] Mihyo, P.B. and Mukuna, T.E. (2015) The Gender-Energy Nexus in Eastern and Southern Africa. OSSREA, Addis Ababa.

[5] Njeru, G. (2014) The Guardian.

https://www.theguardian.com/environment/2014/jan/17/kenya-solar-power-plants? $\mathrm{CMP}=$ share btn tw

[6] Kenya Power Annual Report (2014). http://www.kplc.co.ke/img/full/4rNGlk21KXmA KENYA\%20POWER\%20ANNU AL\%20REPORT\%20FA.pdf

[7] Karekezi, S. and Kithyoma, W. (2002) Renewable Energy Strategies for Rural Africa: Is a PV-Led Renewable Energy Strategy the Right Approach for Providing Modern Energy to the Rural Poor of Sub-Saharan Africa? Energy Policy, 30, 1071-1086. https://doi.org/10.1016/S0301-4215(02)00059-9

[8] UNEP (2007) UNEP Handbook for Drafting Laws on Energy Efficiency and Renewable Energy. United Nations Environment Program, Nairobi.

[9] Dyer, H. and Trombetta, M.J. (2013) International Handbook of Energy Security. Edward Elgar Publishing Limited, Cheltenham. https://doi.org/10.4337/9781781007907

[10] Oxford Business Group (2014) The Report: Kenya 2014. Oxford Business Group, Oxford.

[11] IRENA (2012) Renewable Energy Technologies Cost Analysis Series: Concentrating Solar Power. Comprehensive Renewable Energy, 3, 595-636.

[12] Lynch, J. (2015) Kenya's M-Kopa Is Set to Deliver Solar Power to a Million Homes. Quartz Africa.

http://qz.com/569815/kenyas-m-kopa-is-set-to-deliver-solar-power-to-a-million-ho mes-in-east-africa/

[13] Duffie, J., Beckman, W. and Worek, W.M. (2003) Solar Engineering of Thermal Processes. 4th Edition, John Wiley \& Sons, Hoboken.

[14] Wanga, J. (2012) Letting Solar Help Cut the Cost of Lighting up Your Home. Business Daily.

http://www.businessdailyafrica.com/Solar-powers-cutting-edge-/-/1248928/1407910 /-/qoul50z/-/index.html

[15] Betak, J., Suri, M., Cebecauer, T. and Skoczek, A. (2010) Solar Resource and Photovoltaic Electricity Potential in EU-MENA Region. Proceedings of the 27 th European Photovoltaic Solar Energy Conference and Exhibition, Frankfurt, 24-28 September 2012, 4623-4626. http://geomodelsolar.eu

[16] Philibert, C. (2005) The Present and Future Use of Solar Thermal Energy as a Primary Source of Energy. International Energy Agency, 1-16.

[17] Commission, W.D. (2010) Site Options for Concentrated Solar Power Generation in the Wheatbelt Final Report.

[18] Noorallahi, E., Fadai, D., Akbarpour Shirazi, M. and Ghodsipour, S. (2016) Land Suitability Analysis for Solar Farms Exploitation Using GIS and Fuzzy Analytic 
Hierarchy Process (FAHP)—A Case Study of Iran. Energies, 9, 643.

https://doi.org/10.3390/en9080643

[19] SMA Solar Technology AG (2015) Performance Ratio.

[20] Fitchner (2010) Technology Assessment of CSP Technologies for a Site Specific Project in South Africa Final Report. Washington DC.

[21] ERC (2015) Annual Report Financial Statement 2014-2015.

Submit or recommend next manuscript to SCIRP and we will provide best service for you:

Accepting pre-submission inquiries through Email, Facebook, LinkedIn, Twitter, etc. A wide selection of journals (inclusive of 9 subjects, more than 200 journals)

Providing 24-hour high-quality service

User-friendly online submission system

Fair and swift peer-review system

Efficient typesetting and proofreading procedure

Display of the result of downloads and visits, as well as the number of cited articles Maximum dissemination of your research work

Submit your manuscript at: http://papersubmission.scirp.org/

Or contact nr@scirp.org 